\title{
A produção literária no século XIX sob o olhar camiliano
}

\author{
Jane Adriane Gandra ${ }^{1}$
}

RESUMO: Nossa proposta consiste em discutir como parte da epistolografia camiliana, dirigida a dois críticos literários, Antonio Feliciano de Castilho e Silva Pinto, pode ilustrar os juízos literários que Camilo Castelo Branco dispensava às suas obras e a de outros escritores portugueses da sua contemporaneidade. As missivas tornam-se uma importante fonte documental para elucidar os fatores de tensão na produção literária de seu tempo, como: a relação autor-obra-público, as intervenções editoriais e, por fim, a necessidade de profissionalização nas letras.

ABSTRACT: Our proposal argues how part of camiliana letters, which were addressed to two literary critics, Antonio Feliciano de Castilho and Silva Pinto explain the Camilo Castelo Branco's literary opinion about his own productions, and of other Portuguese writers of his time. These Camilo's letters became an important documentary source to elucidate the tension factors in the literary productions of his time, as for example, the author-work-public relationship, editorial interventions and, finally, the necessity of a professional treatment on letters.

PALAVRAS-CHAVES: Literatura; Camilo Castelo Branco; Crítica literária KEYWORDS: Literature; Camilo Castelo Branco, literary criticism.

$\mathrm{O}$ artigo Notas à Margem, de Antonio Cabral, evidencia-nos o leitor interessado e crítico-metódico que foi Camilo Castelo Branco na sua biblioteca particular. ${ }^{2}$ Nesse texto, ficam nítidas duas idéias; a primeira, de que Camilo era um autor-leitor atento à produção literária de sua época, e a outra, de como a leitura de um novo livro, para ele, era sempre a possibilidade de exercitar a sua veia crítica. As leituras do autor de Amor de Perdição deixavam sempre "à margem de uma página, uma nota, um comentário, uma reflexão de aplauso ou uma vergastada de censura". ${ }^{3}$ Diante dessas informações, acreditamos que parte do universo epistolar camiliano nos daria indícios sobre a criação literária desse autor e o juízo literário que ele dispensava às obras de outros escritores portugueses de sua contemporaneidade. Como Camilo percebia as dificuldades de criação no meio de produção artística de seu tempo? Poderemos supor que a epistolografia de Camilo pode ser uma fonte documental que nos elucidaria os fatores de tensão na produção artística do século XIX,

${ }^{1}$ Mestranda em Estudos Comparados de Literaturas de Língua Portuguesa, FFLCH-USP. Pesquisa: A (De)formação da Imagem: Pinheiro Chagas refletido pelo monóculo de Eça de Queirós. E-mail: jaggandra@ig.com.br

${ }^{2}$ A biblioteca camiliana foi leiloada pelo próprio autor em 1883. Nos seus livros encontravam-se enriquecidas anotações de alto valor crítico-literário.

${ }^{3}$ CABRAL, 1914 p. 11 
tais como, a relação autor-obra-público, as intervenções do meio editorial na obra e, por último, a necessidade de profissionalização das letras?

A partir daí, no entanto, a primeira idéia a ser compreendida é o porquê de se trabalhar com as incontáveis epístolas de Camilo sob este prisma. Para Reinaldo Marques, ${ }^{4}$ as correspondências traçam um perfil não só pessoal, mas também literário. Nelas encontramos indagações individuais, debates de idéias, e discussões calorosas são travadas em prolongadas missivas. E por diversas vezes, os seus conteúdos podem conter comentários sobre a estética de determinado livro ou poema, quando enviados do remetente. E, muitas vezes, após a intervenção do amigo, acaba-se por modificar trechos; terminologias ou mesmo finais de romances. Assim, podemos flagrar um fazer a várias mãos, pois a sugestão do outro quando acatada, ou, a crítica a determinado trecho terminam por criar um outro texto.

Partindo dessa perspectiva, não foi por acaso que privilegiamos nessa análise as cartas camilianas endereçadas a dois críticos de sua época, Antonio Feliciano de Castilho ${ }^{5} \mathrm{e}$ Silva Pinto. ${ }^{6}$ Nem tampouco o período a que elas se referem, pois foi nessa fase da carreira de Camilo em que ele se dedicou mais à crítica literária. As epístolas dirigidas a Antonio Feliciano de Castilho abarcam o período de 1864 a 1870 e as dirigidas a Silva Pinto compreendem a década de 80 . Não nos esquecendo, além disso, que esses períodos foram um momento de transição de estéticas, da romântica para a realista, tempo de grande efervescência literária em Portugal.

Antes de avançarmos, faremos aqui um parêntese para clarificar que Camilo tinha o hábito de endereçar cartas a toda gente. Segundo Alexandre Cabral (1985), esse costume era uma das muitas maneiras que o escritor encontrava para dar vazão a sua necessidade de escrever. Este, ainda, esclarece que através delas fica evidente a instabilidade espiritual do romancista, aquilo que conceituam como o "espírito contraditório, ao cotejarem-se as suas opiniões, invariavelmente discordantes, sobre indivíduos e acontecimentos em épocas mais ou menos próximas." ${ }^{, 7}$ Como, por exemplo, foi sua relação com Silva Pinto na imprensa dos

\footnotetext{
${ }^{4}$ MARQUES, 2003 p.141-156

5 A intervenção de Castilho na vida literária portuguesa, na segunda metade do século XIX, assumiu sobretudo uma feição pedagógica e institucional, causando pelo menos duas das maiores polêmicas literárias portuguesas a Questão Coimbrã (1865) e Questão Faustina (1872).

${ }^{6}$ Escritor de menor popularidade e crítico-literário. Envolveu-se no ano de 1874 em uma polêmica com Camilo. Nesse período era um de seus grandes rivais. Como tudo na vida de Camilo leva a contradição, nos anos finais dos anos 70 fazem-se grandes amigos.

${ }^{7}$ CABRAL, 1985 p. 17
} 
anos 70. Tiveram muitos embates através de opúsculos, mas em uma de suas cartas endereçada a este, Camilo mostra-se outro, diferentemente do habitual espírito cáustico e chistoso que utilizava com seus adversários literários.

Eu não inculco pujança dos seus inimigos; advirto-lhe simplesmente que é melhor não os ter; porque a gente de coração normal até mesmo quando fere os adversários se magoa. Eu sou desgraçado até me entristecer quando firo alguém: prefiro que a retaliação seja cruel, para me não ficarem escrúpulos. ${ }^{8}$

No entanto, hoje, ao pensarmos nas facilidades da vida moderna podemos constatar que as cartas estão em desuso, dificilmente, escreve-se a alguém que não seja através de email. Com isto, em se tratando de correspondência entre literatos perdemos grande fonte documental na análise de criação autoral. Silviano Santiago ${ }^{9}$ sinaliza que, na atualidade, o desaparecimento gradativo dos rascunhos e dos manuscritos dos escritores acarretará na inevitável perda do processo de criação autoral e o fim da pesquisa da genética literária. Esse mesmo autor alerta-nos que "tudo indica que, com o computador, o texto final da grande obra literária perderá grande parte de sua memória."

\section{Vestígios da produção literária camiliana}

Há nesse epistolário indícios quanto à criação novelística camiliana. A partir de alguns trechos das cartas que assinalamos, poderemos perceber o tempo de "gestação no espírito criador" e como se altera a idéia primitiva desde que começa a narrativa até quando o autor coloca seu ponto final. Exemplificaremos com o romance histórico Olho de Vidro (1866), que Camilo precisou de apenas dois meses para criá-lo. Tempo ínfimo levando-se em consideração toda preparação de pesquisa historiográfica necessária para a construção dessa ficção baseada na vida de um médico português do séc. XVIII. Camilo assim escreveu a Castilho: "tenciono escrever uma coisa como romance acerca do Brás Luiz de Abreu, autor do Portugal Médico. [...] Por cá vou trabalhando no Olho de Vidro, enquanto não chega a intercadência da tristeza. [...] O romance está concluído: falta-me desbastar-lhe as principais tolices". ${ }^{10}$ Por meio deste livro, podemos verificar a celeridade de escrita e a

\footnotetext{
${ }^{8}$ CASTELO BRANCO, 1895 p.71

${ }^{9}$ SANTIAGO, 2003 p. $15-24$

${ }^{10}$ CABRAL, 1985, p.43-66 . Foram utilizados trechos das cartas datadas em 05.01.1866, 22.01.86 e 05.03.86, respectivamente.
} 
genialidade de criação de Camilo ao conseguir preencher as lacunas da historiografia. Vale lembrar que no período de 1865 a 1867, Camilo escreveu onze romances, dentre esses sete romances históricos, além de miscelâneas, e o texto polêmico Vaidades Irritantes $e$ Irritadas, esboços de apreciações literárias e colaborações jornalísticas avulsas.

Nas correspondências trocadas entre Camilo e esses dois críticos, temos várias citações sobre as dificuldades do meio literário. Em uma dessas, vamos ao encontro com as desilusões quanto às necessidades pecuniárias em que passava os dias com seus familiares, e como essa ocorrência o deprimia intensamente.

Mesmo doente, tento escrever (...) escrever com repugnância só com extrema precisão, com credores à porta e a fome em casa. [...] Escrevo romances e que remédio senão escrevê-lo sempre? Em Lisboa tenho editor que me paga o volume a $144 \$ 000$ reis [32 libras]. Se dentro de um ano não me pagarem a propriedade de cada volume a 50 libras, creio abrirei uma tenda e acabarei tranqüilo, honrado e estúpido como convém.

Camilo, como sabemos, foi o primeiro escritor português a viver do que produzia como escritor. Isso associado a uma sociedade de poucos leitores, e onde os direitos autorais ainda estavam em processo de reconhecimento, apesar de em 1851 Garrett ter apresentado tais propostas de leis. Nem sempre Camilo teve liberdade em escolher o que queria escrever. Os gostos do público e os interesses editoriais direcionavam muito o trabalho de criação literária camiliana. Escrever era antes de tudo um ganha-pão. Entretanto, quanto mais intervinham em sua produção, mas deixava impressa a ironia mordaz em suas linhas ficcionais.

Em outra carta, Camilo evidencia que, por diversas vezes, alguns de seus romances foram rejeitados pelo editor, por não serem politicamente comerciais, ou seja, de não irem ao encontro do gosto da época. Por outro lado, em muitas situações, Camilo se debruçava sobre obras que não rendiam muitas receitas a ele, mas profissionalmente o fazia. Os fragmentos a seguir podem elucidar bem nossa discussão.

Creio que não terei editor para o meu livro O Marquês de Pombal. É providencial isto, para que eu não tenha de ser agraciado com algumas datas de besta e jesuíta. $O$ Chardron diz-me que antes quer romances. É que está grafado do tipo pombalino. $(20-04-80)^{11}$

\footnotetext{
${ }^{11}$ CASTELO BRANCO, 1895 p. 41
} 
Estou, a espaços curtos, escrevendo um livreco Os Nossos Primos. É um trabalho que não vale dez réis, mas que me obriga a consultar muitos livros velhos e novos. Coisas de pitada solene como a d' um frade d' Alcobaça. $(26.03 .81)^{12}$

As epístolas também deixam claras as propostas de trabalho que não fecundaram. Numa carta de fevereiro de 1873, Camilo diz que estaria projetando um livro, intitulado $O s$ Amores de uma Rainha Portuguesa, porém ele nunca o escreveu. A coleção foi inaugurada com o romance histórico Os Guerrilheiros da Morte (1872), de Pinheiro Chagas, ao qual se seguiu A Vingança do Sargento, tradução desse escritor. O terceiro exemplar seria esse romance idealizado e, que devido à alegação de doença e devido à alegação, Camilo nunca escreveu. Foi, então, que os editores publicaram A Máscara Vermelha (1873), também de Pinheiro Chagas.

Continuo na cama sem grande esperança de me levantar tão cedo. A medicina manda-me esperar a primavera. E isto muito mais de suportar que as tizanas de botica.

Felicito VV... por terem alcançado do meu talentoso amigo Pinheiro Chagas um romance que preenche o lugar que me tinham destinado. O público lucra, e a empresa também. Se me restabelecer, seguirei depois com muita satisfação; desconfio, porém, que a minha carreira está atravancada por um estorvo incomodo e sério que se chama à sepultura. Aceito tudo alegremente. ${ }^{13}$

Camilo tem impaciência por não poder escrever; outro ponto ratificado nesse trecho da carta é o reconhecimento de Pinheiro Chagas nas Letras. Novamente, temos a certeza que Camilo nunca deixou de ler o que estava sendo produzido em seu tempo.

A partir do que discutimos até aqui, entendemos que Camilo é mais um gênio escritor incompreendido na sua época. Ele estava dividido entre o público real, aquele para quem ele tem a necessidade de escrever para sobreviver, e o público virtual, aquele para quem ele espera ser compreendido. Essa angústia autoral aproxima-se muito da essência de duas obras, Coração, Cabeça e Estômago (1862), de Camilo e Memórias Póstumas de Brás Cubas (1881), de Machado de Assis. Duas ficções que são destinadas ao público póstero, narrativas que se aproximam nas temáticas do autor incompreendido na sua época e nas intervenções que seus editores fazem nas memórias do autor-personagem. Não nos esquecendo que tanto a narrativa camiliana quanto a de Machado são construídas na mais ácida ironia à sociedade.

\footnotetext{
12 ibidem p. 119

${ }^{13}$ CASTELO BRANCO, 1925 p.137
} 
Os meus livros vão aparecer em tempo de serem entendidos. Espero que eles não tenham uma gravidade sinistra. $\mathrm{O}$ meu propósito é meramente recrear, e fazer rir em quanto outros operários mais sisudos vão preparando o dia da ira. (13.11.72)

Os nossos nomes estão desfeitos como os ossos hão-de talvez então espertar-lhes uma saudade mais gloriosa para nós que a imortalidade que pode dar um livro. Eu por mim antes quero a saudade de um filho do que a certeza de que os netos da Viúva Moré publicaram a duodécima edição de um livro que a sua avó me comprou por seis vinténs e meio. $(29.01 .68)^{14}$

Aqui, nestes trechos, fica claro o que Camilo pensava das casas editoriais. O lucro, as alterações na obra para adequação ao gosto do público, as exigências editoriais na encomenda de três ou mais obras em pouco espaço de tempo, com certo número de páginas, tudo isso eram pontos de incômodos para nosso autor. E assim, passavam os literatos os dias. Às vezes, obras que não tinham boa vendagem, ou seja, não correspondiam à expectativa do público e de seus editores, esses escritores ficavam desprestigiados em futuras publicações. Camilo, em uma de suas cartas sem data, escreveu o seguinte sobre a situação literária de alguns de seus contemporâneos.

A Viúva Moré enviou um agente a dar balanço à livraria. Claro é que o seu representante na casa do Porto não podia inspirar-lhe a mínima desconfiança. Todavia como os lucros ou remessas de dinheiro não correspondiam à vontade da viúva, o agente manifestou o descontentamento da sua constituinte por José Gomes ter empatado bastante dinheiro na publicação de certos livros, que não se vendem, nomeadamente os de Rabello Silva, Andrade Corvo, dramas de Pinheiro Chagas, Arnaldo Gama, é não sei que outras indevidamente rejeitadas. Esta censura magoou Gomes Monteiro, e, a meu juízo, será, afinal, causa de rompimento. José Gomes não carece daquilo, por que tem sobejos bens de fortuna. ${ }^{15}$

Notemos que para Camilo, esse editor, muitas vezes criticado por ele, também cometia erros na publicação de livros de outros autores. Parece-nos aqui, mais claro, que Camilo tem sua vingança posta à mesa em relação às injustiças de análise sofridas pelos seus livros por parte do editor Gomes Monteiro. Mais tarde, em 1874, Camilo romperá com este por causa das intervenções feitas e da recusa de publicação por um número expressivo de seus livros.

\footnotetext{
${ }^{14}$ ibidem p. 168

${ }^{15}$ BAIÃO, 1930
} 
José Gomes Monteiro enviou-me ontem o manuscrito, fazendo-me saber que o não publicava. Dá razões fundadas na crítica do romancinho: escusa V.Exa. de ouvi-las. Algumas pareceram-me ajuizadas se fossem feitas a livro de autor que se não estreasse, com 18 anos de idade. Não teve que dizer da linguagem: é o entrecho que lhe desagrada.

Casos análogos, já com este são três que me sucedem com J. Gomes Monteiro. Não sucederá o quarto. Livro meu é que a casa More decerto não analisará mais. Aí está $O$ Judeu que em geral está sendo bem acolhido; pois o G. Monteiro considera-o o pior de todos os meus escritos" (19-03-66). ${ }^{16}$

Sabemos que o modo de publicação de um livro em folhetim interfere na narrativa. A recepção da época do seu livro histórico Luta de Gigantes, que saiu no Comércio do Porto, no ano de 1865 , não havia sido feita com bons olhos pelo público-leitor, como fica explicitado por ele. No entanto, esse mesmo livro é considerado por Pinheiro Chagas, ${ }^{17}$ um dos críticos de renome da época, como o melhor romance histórico já feito por Camilo Castelo Branco: "Remeto hoje a V.Exa. a Luta de Gigantes. É coisa aborrecida. As senhoras do Porto têm dito deste romance pior do que eu poderia dizer delas. É láudano puro. (28-01-66)". ${ }^{18}$

A popularidade de Camilo era imensa, a ponto de em uma carta de Castilho a este escritor perceber-se a curiosidade do público português sobre a produção literária de Camilo.

Dos seus trabalhos literários é que V.Exa. me não diz nada, e eu desejava saber tudo, até porque tenho vergonha de não saber responder quando por aqui a cada passo me perguntam "Que está escrevendo agora o Camilo?" (21.05.66). ${ }^{19}$

\section{Camilo e a produção literária de seu tempo}

Parece-nos que Camilo estava atento ao que se produzia em Portugal. Faz críticas ácidas, às vezes, ao próprio autor da obra:

Quando lhe escrevi a respeito do Grande Homem ( comédia de Teixeira de Queirós) não sabia que o meu amigo implicara com a coisa. Posto que sou assinante da Folha Nova, e pagasse adiantado, não a tenho recebido novidade que não vai bem à Folha. Li porém os seus artigos. O primeiro exprime tudo e magnificamente. $O$ Grande

\footnotetext{
${ }^{16}$ CABRAL, 1985 p. 70

${ }^{17}$ CHAGAS, 1867 p..50-3

${ }^{18}$ ibidem p.53

${ }^{19}$ COSTA, 1924 p.96
} 
Homem é aquilo - é a caricatura - Eu já o disse em carta particular ao autor. (17-01$1882)^{20}$

Mas também congratulava-se com outros que, para ele, eram merecedores de elogios.

Já recebi algumas folhas dos Combates. Eu nunca tinha lido Do Realismo na Arte. É um bom trabalho e o seu melhor trecho da crítica, porque se vê que escreve estranho a violências e ressentimentos. $(04.06 .82)^{21}$

O livro Três Mundos, Lisboa (1873) de Antonio da Costa é admirável. A primeira e a segunda parte reli-as; a terceira, sendo mais batida na incide comum,é sublime. Nas duas que são belíssimas há a verdade histórica em bronze; a outra, que representa um esforço repetido em dar à idéia cristã o alcance que ela não teve, nem já agora terá, falha como todas as bonitas hipóteses criadas à volta de um vácuo. (s/ data) $)^{22}$

Nem as suas obras escapavam à sua crítica. Ao se referir a Agulha em Palheiro, que foi dedicado a Castilho, em sua primeira publicação editada no Brasil, considera um livro digno dos tupiniquins, mas não do público e crítica portugueses. Nesse trecho, percebe-se a repulsa que tinha dos brasileiros. Paulo Motta Oliveira ${ }^{23}$ assinala que essa imagem pejorativa do brasileiro é freqüente na produção camiliana, podendo ter uma relação de fundo biográfico, assim recriando na ficção indícios autobiográficos.

Chegou do Brasil aquele livro cuja dedicatória V.Exa. teve a condescendência de aceitar-me. E possível que algum dos poucos exemplares que vieram para Lisboa chegue à mão de V.Exa. Se isso acontecer, peço-lhe que o não leia. É uma vergonha para os prelos do Império e para mim. Estou preparando uma segunda edição, que é o traslado do que eu escrevi para os macacos de Santa Cruz. Se V.Exa. encontrar algum crítico, peça-lhe por bondade sua e dele que não leia; e se tiver lido, que suspenda o juízo, se o tiver. (05-11-1864)

Pela correspondência de Camilo, sabemos que ele excluía de suas leituras alguns escritores, sem explicar muito os motivos, como por exemplo, a aversão aos romances históricos de Arnaldo da Gama, "As novidades literárias do Norte são um romance do Arnaldo Gama, que nunca lerei. A d. Ana e a ema que devoram essas escumalhas de ferro.

${ }^{20}$ CASTELO BRANCO, 1895 p.84

${ }^{21}$ ibidem p. 92

22 ibidem p.89-90

${ }^{23}$ OLIVEIRA, 1999 p..99-111

${ }^{24}$ CABRAL, 1985 p. 31 
Lê tudo" 25 . A ironia camiliana está bem presente nesse trecho da sua correspondência. Seria pelo simples fato de nessa época, Camilo se dedicar à produção de romances históricos e ter os de Arnaldo Gama também muita aceitação pelo público-leitor de seu tempo? Talvez. Podemos assim dizer que estaríamos entrando em um terreno destinado às vaidades e invejas do meio literário, assuntos estes destinados a uma outra conversa.

Por outro lado, ele continuava privilegiando os textos de outros escritores populares, como Pinheiro Chagas. ${ }^{26}$ Em pelo menos quatro cartas do nosso universo de vinte, há citações sobre a produção literária de Pinheiro Chagas. Sempre elogiando e corroborando com a fecundidade literária desse autor. Evidenciando-nos, ainda, que viver dos rendimentos das Letras não era um ofício apenas de Camilo, Pinheiro Chagas apesar de ter um cargo no Estado, ainda assim, trabalhava arduamente na literatura. Tanto que morreu pobre, tendo, após a sua morte, por diversas vezes, seus amigos mais íntimos socorrer seus familiares.

Agradeço a remessa do romance de Pinheiro Chagas, O Segredo da Viscondessa. Havia quem se admirasse da muita fecundidade! Trabalhar é assim. Receio, porém, que tamanho esforço o prejudique aos quarenta anos. Descuido será o gentilíssimo escritor, se muito a horas, não for segurando o futuro de seus filhos e a remansosa velhice. [...] leio, a intervalos, a história de Portugal do Pinheiro Chagas, que reputo um necessário e excelente livro. ${ }^{27}$

Para termos uma idéia da popularidade de Camilo e de Pinheiro Chagas na época em destaque, o artigo de Alexandre Cabral, Acerca de um "Plebiscito Literário" em $1884,{ }^{28}$ demonstra-nos bem isso. O periódico $O$ Imparcial fez uma sondagem sobre quem seriam os três escritores portugueses mais notáveis nessa época. O resultado obtido ao final da pesquisa teve a seguinte classificação: $1^{\circ}$. Camilo Castelo Branco, $2^{\circ}$. Pinheiro Chagas, $3^{\circ}$. Latino Coelho, $4^{\circ}$. Eça de Queiroz, tendo Teófilo Braga em sexto e Antero de Quental em décimo-segundo. Apesar de nessa época existir uma nova vanguarda literária através dos integrantes da Geração de 70, e de Eça de Queiroz estar no auge de sua produção realista e naturalista, parece-nos plausível que o gosto do público não aderiu rapidamente a tais inovações. A leitura dos resultados demonstra que os escritores que dominaram o

\footnotetext{
${ }^{25}$ Ibidem p.145 26.03.1867.

${ }^{26}$ Polígrafo português. Pivô de uma das maiores polêmicas literárias de Portugal, a Questão Coimbrã, devido a uma carta posfácio escrita por Antonio Feliciano de Castilho ao editor Antonio Maria Pereira.

${ }^{27}$ Ibidem, p.42 ( set.1872) e p.58 (26.02.1873).

${ }^{28}$ CABRAL, 1973 nr. 353 p.588-614 e nrs.354-355 p.484-95.
} 
cenário da renovação literária, no debate por melhores condições para Portugal em relação à Europa, nenhum deles teve lugar entre os três primeiros colocados neste plebiscito.

\section{Conclusão}

É evidente que esses fragmentos escolhidos por nós, não nos habilitam a mapear fielmente a produção literária da época, mas parece-nos uma grande possibilidade para uma investigação, no futuro, mais detalhada. Nas correspondências camilianas aqui citadas, podemos verificar algumas das dificuldades enfrentadas pelos escritores no século XIX, tais como escrever para viver, sem nenhum direito resguardado. Lembrando que Camilo ganhava a vida com seu trabalho de escritor, o que pode tê-lo obrigado a subordinar-se ao gosto e aos padrões morais do seu público e, levando-o em muitos casos, aos excessos da moda literária da época, devido a pressões de suas exigências pecuniárias e às dos seus variados editores. Camilo vendia a sua pena, mas sempre tendia a fazê-lo por quem pagasse mais, mas isso não impediu que o nosso autor se frustrasse diversas vezes por não ter tido o reconhecimento que ele merecia.

Podemos também aqui, em particular, compartilhar, em alguns trechos dessas cartas, com a veia crítica de Camilo quanto a obras de seu tempo. Assinalando o alto valor literário de nosso autor, pedindo juízos, indicações sobre o que escrevia e dando suas considerações acerca da obras de seus patrícios. É certo que, por diversas vezes, deixou esse juízo ser contaminado por suas emoções. Já o perfil Camilo-leitor, cada vez mais, ratifica-nos a idéia de que a literatura nutre-se de literatura.

Nosso intuito foi, através desse período destacado na trajetória da produção camiliana, poder clarificar, nem que fosse de forma superficial, o fazer literário desse gênio, que tinha uma escrita frenética até mesmo na criação de romances históricos que necessitam do apoio da história. Descobrimos projetos literários que só ficaram na planificação, como por exemplo, O Púlpito Português e Os Amores de Uma Rainha Portuguesa, deixando-nos interessantes pormenores sobre o plano que projetava traçar. $\mathrm{O}$ seu determinismo conseguiu construir a idéia de um profissionalismo nas Letras como poucos, tendo como exemplo maior a necessidade de elaborar em apenas dois meses o romance histórico Olho de Vidro, intercalando a feitura desse com outros labores literários.

Não é objetivo deste ensaio fechar analiticamente as correspondências desse escritor no retrato de sua época. Não se pode desvendar todo o Camilo correspondente, pois como 
na obra, suas epístolas são portadores também de contradição. Em muitos trechos de suas cartas, Camilo torna-se um tipo de remetente em que o leitor não pode confiar piamente, seja por meio de um juízo, de uma palavra, de uma exclamação ou até mesmo do uso de reticências, existe um segredo a desvendar. Por isso, podemos também considerar sua epistolografia um prolongamento de sua ficcionalidade, pois era evidente a necessidade de Camilo extravasar-se através de sua pena.

\section{Referências bibliográficas}

BAIÃO, Antonio. Camilo e Castilho. Correspondência do primeiro, dirigida ao segundo. Inéditos do Arquivo Nacional da Torre do Tombo. Coimbra: Imprensa da Universidade, 1930.

CABRAL, Alexandre. Correspondência de Camilo Castelo Branco com Antonio Feliciano de Castilho. Vol.III. Livros Horizonte, 1985.

In: Vértice. Revista de Cultura e Arte. Vol.XXX III/ XXX IV. Coimbra: Atlântida.jun./julho/ago-1973 nr. 353 p.588-614 e nrs.354-355 p.484-95.

CABRAL, Antonio. Camillo de Perfil. Lisboa/Paris: Livrarias Aillaud e Bertrand, 1914 CASTELO BRANCO, Camilo. Com pref. e notas de Silva Pinto. Lisboa: Livraria Editora de Tavares Cardoso e Irmão, 1895. . In: Arquivo literário. Tomo X. vol.III. Lisboa: Livraria Editora Guimarães \& Cia. Jan-jun de 1925 p.137.

CHAGAS, Manuel Pinheiro. Novos Ensaios Críticos. Porto : Em Casa da Viúva More, 1867.

COSTA, João. Castilho e Camilo. Correspondência trocada entre os dois escritores. Coimbra:Imprensa da Universidade, 1924 p.96.

MARQUES, Reinaldo. O Arquivamento do Escritor. In: Arquivos Literários. Orgs. Eneida Maria de Souza e Wander Mello Miranda. São Paulo: Ateliê Editorial, 2003 p.141-156.

OLIVEIRA, Paulo Motta. Nótulas acerca do Brasil em dois romances Camilianos. In: Estudos Portugueses e Africanos $1^{\circ}$. e $2^{\circ}$. semestres de 1999, nos. 33/34 . Campinas, 1999.

SANTIAGO, Silviano. Com Quantos paus se Faz uma canoa. In: Arquivos Literários. Orgs. Eneida Maria de Souza e Wander Mello Miranda. São Paulo: Ateliê Editorial, 2003. 